\title{
Chinese Collaborative Software in Digital Transformation Era
}

\author{
Juanqiong Gou, Nan Li, Wenxin Mu, Qinghua Liu and Xiyan Lv \\ Beijing Jiaotong University, School of Economic and Management, Beijing, China \\ \{jqgou, 17120615, wxmu, 14241058, Ivxiyan\} @bjtu.edu.cn
}

\begin{abstract}
China is witnessing a large number of digital transformation cases, spearheaded by business model innovation but also by the emergence of systems that in one way or another to support collaborative network organizations. This paper establishes an analysis framework for collaborative management systems of dynamic organization, based on the literature review of digital transformation and collaborative management. It then analyzes the fitness of two existing and leading collaborative management software provided in the Chinese market. For each of the two systems, the paper specifies the system requirements and the applied modeling methods. The connotation of traditional collaborative software is extended in terms of collaboration goals, scope, content, and methods, as well as product innovation through cases analysis. Meanwhile, it gives direction for future collaboration system modeling.
\end{abstract}

Keywords: Collaborative network organizations, collaborative management system, collaborative network

\section{Introduction}

Driven by the explosive spread and use of the Internet in industrial practices, there are a large number of organizational and management innovation cases in China. Digital transformation has, in turn, posed a huge challenge to the development of both applicable organization management theories and enterprise management systems. In recent years, the authors have conducted a large number of case studies and consulting works on digital enterprises and were involved in cooperative research together with software companies through being in charge of some smart campus construction projects. The authors have witnessed the timeliness of innovation in digital transformation, the great interest from the Chinese enterprises, and the urgent need to develop supporting software systems for enterprise collaboration. The cooperation with software companies also brought an in-depth understanding of the product design concepts and modeling methods, as well as the complexity and ambitions to generate new theories and models as well.

Through research and practice in European academic circles during the last two decades, Collaborative networked organizations (CNOs) was established as a study 
discipline. CNO studies primarily addressed all stages of the life cycle of dynamic goaldriven Virtual Organization (VO) networks, from supporting its formation and configuration to its creation, operation, metamorphosis, and dissolution within the market and society[1]. When considering the distinct specificities of the Chinese business atmosphere, the authors specifically address a number of Chinese software industry that currently provides certain collaboration management systems to this market. The authors investigate whether and how the $\mathrm{CNO}$ discipline can provide some needed theoretical and system support for enterprise networking, which is currently lacking from the Chinese provided collaboration management systems, and thus can be used to enhance future product developments in these industries.

The method adopted by the article is a case study method. The case study method was chosen for two reasons. Firstly, the case study approach generates insightful stories rather than statistical information, and this permits a better understanding of organizational complexity from an insider's viewpoint[2]. Secondly, case studies enable the researcher to formulate a more holistic perspective on the studied phenomenon[3]. They are especially useful in exploring research areas that are theoretically less developed [4].

This paper selects two specific software enterprises. The research is based on a twoyear study conducted in the two enterprises from 2016 to 2017. The focus of the study is on exploring the development and implementation of their system within the organizations and their customers. The data-collection methods employed in the study were: interviewing, onsite observation, and documentation. Especially the platforms are used in the real application of system development of the author's projects. All interviews were conducted on a face-to-face basis. Data were also collected from a range of documents, including letters, written reports, administrative memoranda. The latter was especially useful in case A for understanding the feedback from end users and their partners.

By using two case studies, the richness of the collaboration scenario is enhanced. The entrepreneurs of the two cases both have a background of the traditional enterprise system and then focus on the collaboration platform with different perspectives.

The case study is focusing respectively on business, organization, and management of collaborative research. For this purpose, based on the CNO theory, this paper first designs a framework for collaborative software analysis and research. Second, the cases are analyzed from the perspectives of their application scenarios, system requirements, modeling methods and their concerns for the future.

\section{Literature Review}

This part reviews the literature on digital transformation and collaborative management from the perspective of $\mathrm{CNO}$ theory. 


\subsection{Digital Transformation}

The rapid development of digital technologies represented by cloud computing, analytics, mobile, social media, and the unprecedented interconnection and interoperability[5] are constantly changing the interactive interconnection of people, companies, governments, and surrounding communities. The new trend is the digital transformation, which has led to challenges and brought new opportunities for business model innovation[6].

Through the interconnection and intercommunication, a great deal of information has been generated, thereby deepening the improvement of business operations and all aspects of daily life. More enterprises begin to encapsulate the service capability based on the standard and form the API management mode for both internal and external consumption, which that will facilitate the rapid implementation of business and eco-environment interconnection at the business level[7]. Digital transformation has brought new opportunities for business model innovation[6]. The rapid development of mobile social networks takes full advantage of digital technologies to build out a global business ecosystem[8], so a new digital business model has begun to take shape.

Digital transformation is the result of the application of digital technology in all aspects of human society. It supports the creation and innovation of specific industries or fields, and this type of innovation breaks through the boundaries of traditional enterprises for new enterprises and moves to a broader ecology[9] in line with globalization environmental expansion.

\subsection{Collaborative Management}

A collaborative network $(\mathrm{CN})$ is a network consisting of a variety of entities (e.g. organizations and people) that are largely autonomous, geographically distributed, and heterogeneous in terms of their operating environment, culture, social capital and goals, but that collaborate to better achieve common or compatible goals, and whose interactions are supported by computer network[10]. In today's society, collaborative networks manifest in a large variety of forms, including the production or service-oriented virtual organizations, virtual enterprises, dynamic supply chains, professional associations, industry clusters, professional virtual communities and collaborative virtual laboratories, etc.[11][12]. Most forms of collaborative networks imply some kind of organization over the activities of their constituents, identifying roles for the participants, and some governance rules. Therefore, these can be called collaborative networked organizations (CNOs) [10].

Both formation and evolution of the $\mathrm{CNO}$ primarily involve dynamic reconfiguration of heterogeneous /autonomous resources, in response to the raised opportunities while being aware of the uncertainty of environmental dynamism. Based on[13], collaborative networks, such as virtual organizations, dynamic supply chains, professional virtual communities, collaborative virtual laboratories, etc. are complex systems associated with uncertainties in dynamic business environments. 
Research on CNOs and modeling of the dynamic organization, have defined two main organizational forms and management/governance models. The CNO theory includes two levels' management consideration, strategic (VBE) and tactical (VO) level, and the authors compare the two based on this literature, as shown in Table 1. The Virtual Organization (VO) and the Virtual Organizations Breeding Environment (VBE) are therefore established as the core distinguished classes with a number of subclasses addressing different dynamics and diversity of their business targets and management, as well as a wide variety of more specific organization examples[14][15].

Table.1. Two different management mode in CNOs

\section{Goal}

Organization Operation

\begin{tabular}{|c|c|c|c|}
\hline \multirow{2}{*}{$\begin{array}{l}\text { Short- } \\
\text { term } \\
\text { (VO) }\end{array}$} & Static & $\begin{array}{l}\text { Identification of opportunities and } \\
\text { goals }\end{array}$ & $\begin{array}{l}\text { Formation of } \mathrm{VO} \text { driven } \\
\text { by the goal }\end{array}$ \\
\hline & Dynamic & Execution, adjustment of goal & $\begin{array}{l}\text { Dynamic coordination of } \\
\text { members, resources and } \\
\text { processes }\end{array}$ \\
\hline \multirow[t]{2}{*}{$\begin{array}{l}\text { Long- } \\
\text { term } \\
\text { (VBE) }\end{array}$} & Static & Convergence of long-term goal & $\begin{array}{l}\text { Collaboration with the } \\
\text { dynamic } \\
\text { environment }\end{array}$ \\
\hline & Dynamic & $\begin{array}{l}\text { Formation of strategic alliances, } \\
\text { identification and integration of } \\
\text { membership and resources, etc. }\end{array}$ & $\begin{array}{l}\text { The evolving } \\
\text { management of CNO }\end{array}$ \\
\hline
\end{tabular}

In the end, the introduced digital transformation and collaborative management theories provide strong theoretical basis for rapid development of the enterprise collaboration support software.

\section{Case Analysis}

This section will analyze the two cases. Firstly, it will describe the understanding of the demands or/and patterns of the organizational collaborative management in the initial stage of product design and the understanding of the digital transformation. Then their collaborative systems in the technical architecture and the CNO theory will be located.

\subsection{Case Analysis of DAJIA}

This part mainly describes the DAJIA company's understanding of the organizational 
management demand and its platform products in digital transformation era, analyzes the DAJIA modeling methods, and ultimately, discusses DAJIA from the perspective of $\mathrm{CNO}$.

\subsubsection{Analysis of organizational management demand}

DAJIA is a startup company that mainly adopts the method of customer-oriented management and operation to help traditional offline companies to carry out the digital transformation.

With social capital's adequacy and local government's aids This is the golden period for Chinese traditional industrial "digital transformation".; The advantages of traditional industries have also been steadily established, and the objective foundation of "Internet+" transformation is solid. So far, the Chinese economy is in a period of transition from a scarcity economy to a rich economic. The concept of customer consumption is greatly challenged, and consumption capacity and consumer demand are greatly upgraded. Products with high quality, high service, and cultural added value are increasingly recognized by consumers.

Chinese e-commerce has gone through two stages under the trend, which is the $\mathrm{B} 2 \mathrm{~B}$ (Business to Business) phase that indirectly benefits consumers and the $\mathrm{C} 2 \mathrm{C}$ and $\mathrm{B} 2 \mathrm{C}$ (Customer to Customer and Business to Customer) phase that directly reduce the selling price. With entering the omnidirectional digital transformation era, the third phase of ecommerce is $\mathrm{O} 2 \mathrm{O}$ (Offline to Online or Online to Offline) business, which will be continually amplifying the traditional offline business market.

$\mathrm{O} 2 \mathrm{O}$ business mainly includes two ways, online-to-offline and offline-to-online, in which there are Internet e-commerce companies and traditional brand companies as the main bodies. Table 2 show their advantages and disadvantages in digital transformation by comparing their differences in organizational management.

Table.2. Comparing the two main bodies of $\mathrm{O} 2 \mathrm{O}$ business

\begin{tabular}{|c|c|c|}
\hline & $\begin{array}{l}\text { Internet } \\
\text { company }\end{array}$ & Traditional brand company \\
\hline Brand influence & Platform influence & Brand influence \\
\hline $\begin{array}{l}\text { Offline service } \\
\text { system }\end{array}$ & None & Very mature \\
\hline The client system & The platform & A lot of regular customers \\
\hline Service scenario & $\begin{array}{l}\text { Informatization } \\
\text { fragmentation }\end{array}$ & Relatively complicated \\
\hline Thought & Internet/community thought & Conventional thought that is \\
\hline
\end{tabular}




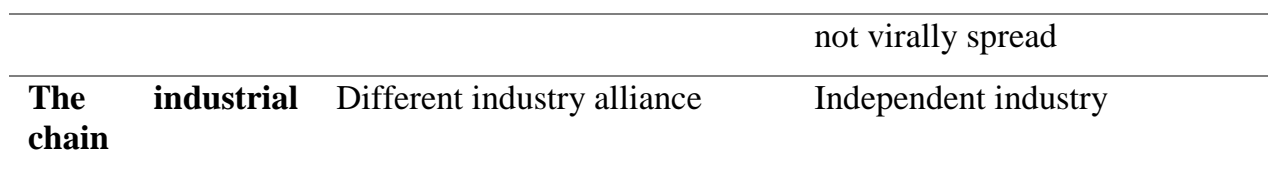

Business maturity Low and cannot be marketable Mature and can be marketable

Traditional enterprises, which possess many advantages such as high awareness of brand, offline customer service system and mature business, can expand their own brands and support off-line resource through virtual community platform. They may become a new Internet leader in the digital transformation. However, Internet e-commerce companies these days are mainly facing two difficulties. Firstly, it is too expensive to attract and sustain customer flow. Secondly, comparing with some largest intermediary platforms, like Alibaba, Taobao, Jingdong, therefore, most small and medium-sized e-commerce enterprises do not possess self-owned platform that can undertake cross-platform customer flow, which is a fatal issue.

Digital technologies can offer traditional brand retails new opportunities to attract customers online, which well quickly broaden the traditional offline business market. DAJIA, depending on the digital technologies, helps traditional enterprises in different industries with different collaborative platforms aiming their business demands, in which the enterprises can take on multiple customers and quickly gain benefit from them both online and offline. At the same time, DAJIA's platforms provide customers with fullcycle services, which can attract and sustain customer flow, broaden business operations, brand awareness and revenue for enterprises.

\subsubsection{Enterprise Modeling Method}

With the rapid development of IT technology and mobile Internet, the "scenario" has attracted wide attention from the business community[16], especially the Internet industry that defines the "scenario era" as the connection of everything following the IT (Information Technology) and DT (Digital Technology) eras. The so-called scenario thinking actually refers to a kind of service thinking based on the user scenarios, which is the human need and behavioural activities. User scenarios often appear in the system's interaction design field to represent stories about people and their activities to describe who will use the system to accomplish a task[17]. 


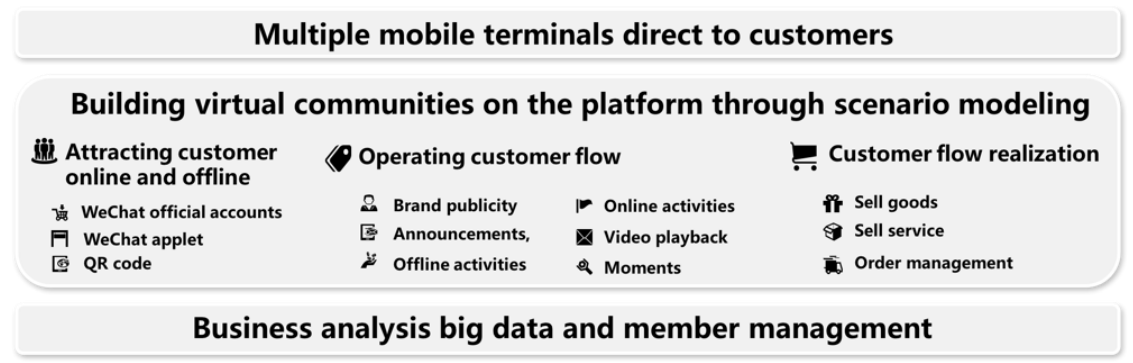

Fig.1. Modeling Method of DAJIA

The products of DAJIA build a customer service scenario platform for customer community flow. The platform is mainly divided into three parts, as shown in Figure 1, the introduction of customer flow, the operation of customer flow and the realization of customer flow. In introducing customer flow stage, the activity of introducing customer will be implemented on the community platform through scenario modeling, such as personalized interface, QR code, and promoters, etc., to increase new users and expand the community. Operation of customer flow is extracting existing scenarios (eg. short texts) from social networks (eg. WeChat, Weibo) to build a new scenario suitable for the transformation of traditional enterprises, in which customer traffic will be disseminated, converted, and tracked for retaining customers. Realizing customer flow is creating scenarios that generate consumer impulses to increase rebuys.

The core of modeling of DAJIA's products is collaborative scenario modeling based on user behaviour, so user behaviour is a focus of its attention. Scenarios for interactive design specifically divided into two levels[18]. The first level is an objective scenario, which is generally obtained through observation methods to reflect the user's status. This scenario is usually obtained by extracting user requirements before the system is established. The second level is the target scenario, which is a user scenario for solving design problems and requirements based on the first-level scenario. Specifically, user scenarios can be further subdivided into behavioural scenarios and interaction scenarios. The behaviour scenario mainly describes the user's behaviour flow, while the interaction scenario mainly refers to the scene in the interaction process between the user and the system. The former describes the story using the story version, and the latter uses the information flow chart, process story version and other tools to describe[19]. The collaborative scenario, based on user needs and behaviours, is used to represent the interaction and collaboration process of multiple subjects under a certain scenario.

\subsubsection{Analysis Based on CNO}

The customers of DAJIA are involved in the traditional enterprises, especially the traditional sales enterprises. The most typical representative is a woollen company, Jia Tehui. The company's ideal business model is to build China's largest weaving community. 
590 J. Gou et al.

DAJIA helped it to activate customers who have accumulated over the years on Taobao, WeChat and Weibo, and realize its both online and offline channels to improve the profitability through creating a virtual community like VO by scenario modeling. In the virtual community, it provided a scenario-based e-commerce platform integrating shopping, community, high-quality content, and video course services. It freed itself from the exploitation of major e-commerce companies such as Taobao and created its own ecommerce platform, which recruited a number of woollen brands and formed the industrial chain of the weaving industry like VBE.

From the perspective of CNO management discipline, although the CNO theory emphasizes the dynamic and application of VO, it does not give a clear explanation for the specific organization and management within VO. DAJIA's customer service platform, like $\mathrm{VO}$ in the CNO theory, form a standardized VO exploiting scenario modeling, which presets goals, tasks, and participants in the organization and implies a set of orderly management methods and scenario applications within VO. At the same time, the platform provides business analysis and membership management by System of Insight. The function, taking advantage of data analysis, can help users find potential partners and customers, which provides powerful data support for the formation of new VO in the future like VBE.

In the information system modeling of ARCNO[13], DAJIA's platform is more inclined to In-CNO perspective, while integrating shopping, community, high-quality content, and video course services in the platform. It uses scenario modeling to provide the role of customers in a full lifecycle scenario service, which free traditional companies from the exploitation of most famous e-commerce enterprises such as Taobao, Jingdong.

\subsection{Case Analysis of SEEYON}

This section will conduct a case analysis of SEEYON Company from the following three parts. The first part explains the understanding of the organizational management of SEEYON; the second part analyzes modeling method through products of SEEYON; the third part discusses it by CNO theory.

SEEYON, founded in 2002, has been a focus in the field of collaboration management software for 16 years. It formed a complete product line, which is based workflow for collaborative organizations, from private to public clouds, from the Internet to the mobile Internet, from within the organization together to inter-organizational coordination. SEEYON is the NO.1 market share in China's collaboration management software market. It nearly has 50,000 government agencies and enterprise users, more than 5 million end users use SEEYON collaboration management software products and services every day.

\subsubsection{Analysis of Organizational Management Demand}

During the 16 years since establishment, SEEYON has been dedicated to continually 
developing collaborative management platforms and providing services for enterprises. At the same time, the organizational ecology of SEEYON continues to expand with the expansion of the company scale.

The collaborative management platforms of SEEYON focuses on the collaboration management of internal business processes based on "people-oriented" core conception and workflow to build a collaborative enterprise/organization, which is beneficial to improve supervision and control of people in the process of organization management and enhances the flexibility of organization in managing the uncertainty in the organization. In 2013, SEEYON launched a collaborative management platform named "V5" derived from "people-oriented" collaborative management conception, which provides the information collaboration within the organization. It includes five major aspects: portals, workflows, reports, platforms and AI. The application scenarios mainly include a certain scale, the pursuit of sustainable development of enterprises and government agencies, which demand focus on the administration, business team collaboration, business regulation, standardization, intensive management as the core.

When SEEYON's scale is becoming larger and larger these years, it will further expand its own ecological map and continue to enrich its own ecosystem to maximize the value of customers. The customers, such as Microsoft, Oracle, and Huawei, will all be included in SEEYON's ecological circle. SAP, the internationally renowned information service provider, has also joined SEEYON's ecological team to achieve collaboration management because SAP's customers need SEEYON to provide information portals and system integration services. It is deeply felt that only by SEEYON's own ability cannot help enterprises to complete the "Internet $+"$ transformation and information portal integration, which requires industry chain partners working together to build a collaborative ecosystem. This ecosystem can respond to market competition and better serve customers and achieve industrial chain collaboration.

\subsubsection{Enterprise Modeling Method}

Because of the in-depth study of collaborative management and innovational development of collaborative management platform, SEEYON put forward enterprise architecture based on the collaborative technology platform, as shown in Figure 2.

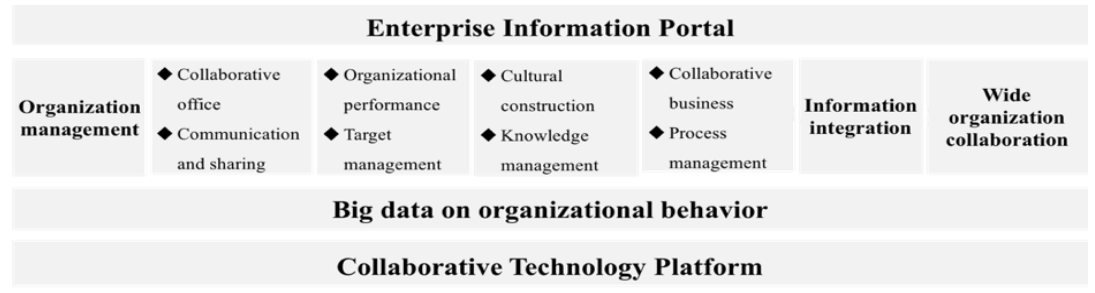

Fig.2. Enterprise Architecture of SEEYON 
592 J. Gou et al.

As the basic feature of the collaborative full-staff application, SEEYON integrated enterprise information portals, including PCs and mobiles, as shown in Figure 2, realizing some key functions such as unified messaging, login and report. Then SEEYON's platform integrates much organization information such as office document, organizational performance, business process and knowledge management, which realizes communication and sharing of this information, target management, knowledge management and process management for wide organizational collaboration.

The digital platform is the engine of digital-driven enterprise transformation, especially as an information system that integrates staff and organizations. It collects, collates, and analyzes various data including management tasks, business processing, employee behaviour, and organizational processes, through the report centre to visualize data and information, which improves the operational efficiency of enterprises /organizations and realize data-driven business and data-driven enterprises.

\subsubsection{Analysis Based on CNO}

The collaborative platform of SEEYON is aimed to collaborate whole social and it has always served for the collaborative ecosystem. Together with customers, industry solution partners, ERP partners, system integration partners, product partners, etc., they have jointly promoted and achieved high-performance organizational management. Therefore, the collaboration in SEEYON is more on the VBE level[14]. However, the collaboration of VBE level is loosening and lack of management method in SEEYON's platform

In the aspect of VO, SEEYON's products have been in the practice of the peopleoriented concept. It gives full play to the group dynamic, which formed the custom quickly customized on-demand organization pattern and various business processes. SEEYON's integration of multiple products has formed internal and external interconnections within the organization, but the organizational boundaries are still relatively clear. The company's products mainly form ad-hoc collaboration[1] through workflow, analyze behavioural performance, and help enterprise establish a dynamic task-driven management model through the workflow.

Although its collaborative management breaks the traditional rigid "best practice" in the past enterprise management and provides on-demand enterprise services to customers, it may face a new problem when the dynamic processes need to be optimized again.

\section{Conclusion}

The paper uses digital transformation and CNO theory to construct the main dimensions of dynamic organization collaborative modeling. Horizontal is the organizational evolutionary trend brought by digital transformation and vertical is the two forms of collaborative management model in dynamic organizational evolution, as shown in Figure 3. Companies 
in internal management and companies providing social products have different development ways to building a collaborative platform. However, in the process of development, the understanding of the collaboration model and product demands of complex dynamic organizations gradually converges.

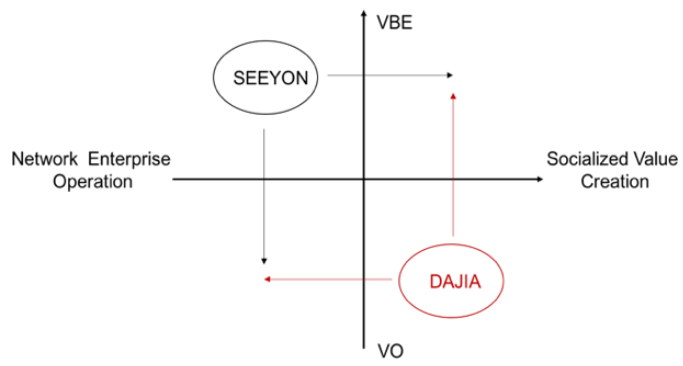

Fig.3. Innovation in Business Model

Based on the literature review of digital transformation and collaboration theories, the paper describes the connotation of the development of an organizational collaboration platform and the two directions of industrial development, as shown in Figure 3. SEEYON, which is committed to corporate operation and management, has gradually begun to development mobile social product to create socialized value. DAJIA, which promotes social networking platforms, has added forms and process management and begun to pay attention to internal organization management.

The contribution to the theory of collaborative management and organization modeling represented by $\mathrm{CNO}$ is to map the theory and the actual needs of Chinese information system together. In the context of digital transformation, the two cases achieved a realistic analysis of the $\mathrm{CNO}$ theory and its value.

The digital transformation has brought many challenges to the field of information systems. The article provides a new perspective, namely the use of collaborative management theory and collaborative platforms to solve these problems. The collaborative management system will become an important type of information system, its connotation will continue to expand in terms of collaborative goals, scope, content, methods, etc. At the same time, the paper provides direction for modeling of collaborative management information systems through the case study.

\section{References:}

[1] L. M. Camarinha-Matos and H. Afsarmanesh, A Modeling Framework for Collaborative Networked Organizations. In: Network-centric collaboration and Supporting Frameworks, pp 3-14, 25-27, Springer US, 2006.

[2] J. C. Mitchell, 'Case and situation analysis 1', Sociol. Rev., vol. 31, no. 2, pp. 187$211,1983$.

[3] R. Evered and M. R. Louis, 'Alternative Perspectives in the Organizational Sciences: 
594 J. Gou et al.

"Inquiry from the inside" and "Inquiry from the outside", Acad. Manage. Rev., vol. 6, no. 3, pp. 385-395, 1981.

[4] R. E. Stake, 'The art of case study research.', Mod. Lang. J., vol. 80, no. 4, 1995.

[5] S. Berman and A. Marshall, 'The next digital transformation: from an individualcentered to an everyone-to-everyone economy', Strategy Leadersh., vol. 42, no. 5, pp. 9-17, Sep. 2014.

[6] Emory University et al., 'Digital Business Strategy: Toward a Next Generation of Insights', MIS Q., vol. 37, no. 2, pp. 471-482, Feb. 2013.

[7] O. A. E. Sawy and F. Pereira, 'Digital Business Models: Review and Synthesis', in Business Modelling in the Dynamic Digital Space, Springer, Berlin, Heidelberg, 2013, pp. 13-20.

[8] G. Remane, A. Hanelt, R. C. Nickerson, and L. M. Kolbe, 'Discovering digital business models in traditional industries', J. Bus. Strategy, vol. 38, no. 2, pp. 41-51, Apr. 2017.

[9] O. A. E. Sawy and F. Pereira, Business Modelling in the Dynamic Digital Space: An Ecosystem Approach. Springer Berlin Heidelberg, 2013.

[10] L. M. Camarinha-Matos, Collaborative networks: Value creation in a knowledge society. In: Knowledge Enterprise: Intelligent Strategies In Product Design, Manufacturing, and Management, pp 26-40, Springer: Boston.

[11] L. M. Camarinha-Matos and H. Afsarmanesh, 'Collaborative networks: a new scientific discipline', J. Intell. Manuf., vol. 16, no. 4-5, pp. 439-452, 2005.

[12] L. M. Camarinha-Matos, H. Afsarmanesh, and M. Ollus, 'Virtual Organizations: Systems and Practices', Springer, 2005.

[13] A. Jamshidi, S. A. Rahimi, D. Ait-Kadi, and A. Ruiz, A New Decision Support Tool for Dynamic Risks Analysis in Collaborative Networks. Springer International Publishing, 2015.

[14] H. Afsarmanesh and L. M. Camarinha-Matos, 'On management of 2nd generation Virtual Organizations Breeding Environments', Annu. Rev. Control, vol. 33, no. 2, pp. 209-219, 2009.

[15] H. Afsarmanesh and L. M. Camarinha-Matos, 'A framework for management of virtual organizations breeding environments'. In: Collaborative Networks and their Breeding Environments, Springer, pp. 35-4, IFIP AICT 8no. 174, pp. 35-48, 2005.

[16] Jianzhong Zhang, 'The age of the scenario era', ZheShang Magazine, no. 12, pp. 3030, 2016.

[17] J. M. Carroll, 'Five reasons for scenario-based design', Interact. Comput., vol. 13, no. 1, pp. 43-60, Sep. 2000.

[18] Yumei Wang, Weifeng Hu, Jin Tang, and Shiguo Li, 'Research on scenario theory in product interaction design', Packaging Engineering, vol. 38, no. 6, pp. 76-80, 2017.

[19] Wanru Zhao, 'The application of scene story in user experience design', Design, no. 9, pp. 174-175,2014. 